\title{
Remanufacturing of Roll Shaft Components of Copying Machines
}

\author{
Zhang Wei ${ }^{1}$, Tan Zhikun ${ }^{2}$, Wu Zhiyuan ${ }^{3, a}$ and Li Yong ${ }^{4}$ \\ (1National Key Laboratory for Equipment Remanufacturing, Academy of Armored Force \\ Engineering, beijing, 100072 ,China) \\ aWu_zhiyuan20021@163.com, ${ }^{b}$ tanzhikun2016@163.com \\ aWu_zhiyuan20021@163.com
}

Keywords: Roll Shaft Components, Refabrication, Cold Spraying, Failure Analysis .

Abstract. Remanufacturing technology is an emergingtechnology, which is widely used in industrial field, since it prevents the recast of waste and outdated components through remanufacturing them again and guarantees that the quality of remanufacted components is not lower or even higher than new products. By taking advantage of the core procedure of remanufacturing technology which is applied to the repair of metal roll shaft components of copying machines, this paper analyzes invalid roll shaft components of copying machines, knows their failure forms, and according to their failure forms, determines correct repair technologies against invalid components.

\section{Introduction}

Copying machine is a kind of widely used equipment. As elapsed time increases, plenty of components will be damaged. However, the mainstream maintenance technology at present causes serious waste, with high maintenance costs. There are also some repair technologies which are specialized for the core components of copying machines, such as the repair technology of toner cartridges. As an important component in copying machine, toner cartridge is the main consumable. As the elapsed time increases, its print effect will get worse. Its use value is recovered by disassembling and cleaning its key components through special cleaning technology [1]. This method has a better effect somewhat compared with traditional repair methods. However, there are still some components which have to be changed instead of repair, such as metal roll shaft components, of which the two ends cooperate with bearing. As time goes by, gap may be caused on the cooperation; relative motion between shaft neck and bearing will be generated; and plenty of heat may be generated with heavy load, which leads to wear on both ends of shaft neck. By taking advantage of the additive repair technology in refabrication technology, mainly including spraying technology and likelaser welding technology, worn parts repaired can be reused, which prevents resource waste, and saves repair expense. In this paper, analysis is made with respect to the failure form of roll shaft components of copying machines, and appropriate repair technologies are determined according to failure features.

\section{Analysis on failure of roll shaft components}

Repair technologies should be selected according to the failure form and mechanism of invalid components. Before the selection, analysis on invalidity should be made on the failure part, form, and mechanism of components. 


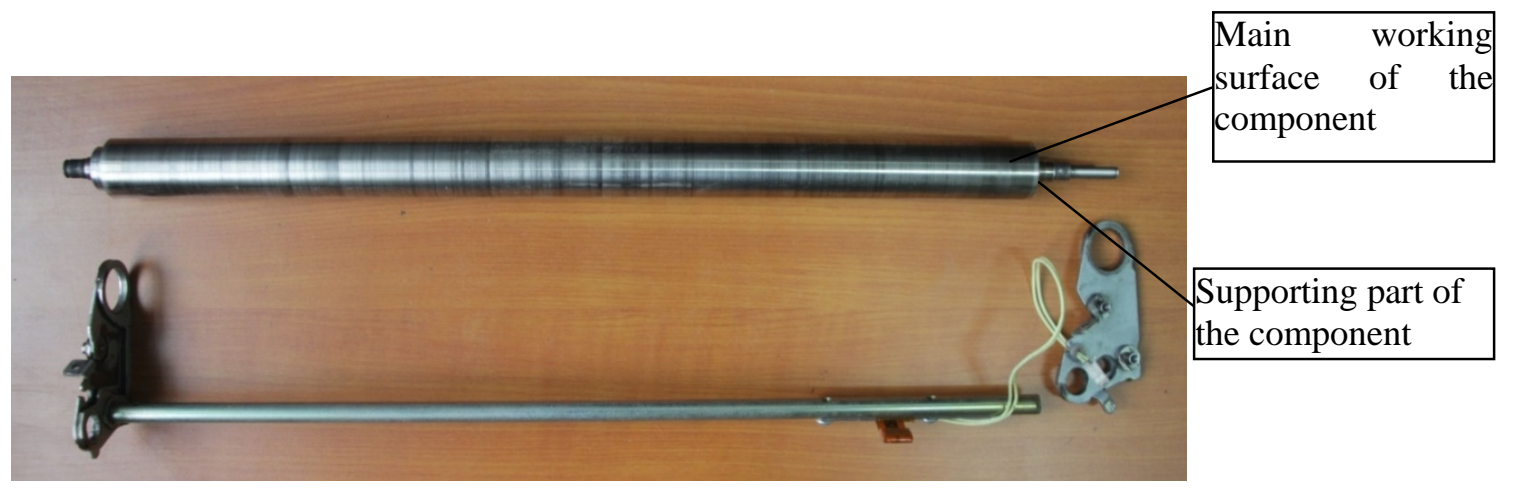

Fig. 1 the invalid stainless steel roll shaft component:

This component consists of main working surface and supporting part. The main working surface is of high smooth finish with no obvious failure form, as its load is light; while the supporting part is in dark color with obvious wearing pit. Fig. 2 is the topography of both ends of the component.
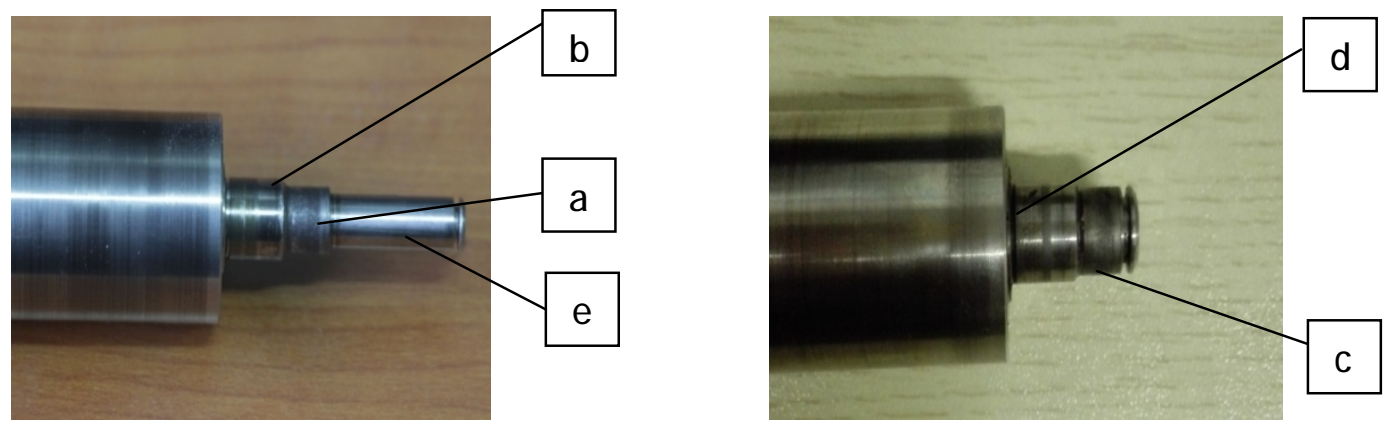

Fig. 2 the invalid part of shaft component:

In this figure, shaft neck a and c cooperate with the NSK large inner diameter bearing with the inner diameter of $9 \mathrm{~mm}$, the outer diameter of $17 \mathrm{~mm}$, and the thickness of $5 \mathrm{~mm}$. Shaft neck b and d cooperate with the NSK small inner diameter bearing with the inner diameter of $8 \mathrm{~mm}$, the outer diameter of $19 \mathrm{~mm}$, and the thickness of $6 \mathrm{~mm}$. Shaft neck e is a non-cooperative shaft neck. It can be observed from the figure that the smooth finish of shaft neck a and $\mathrm{c}$ is obviously lower than that of shaft neck b, d, and e. However, there are still some obvious polishing scratch on shaft neck $b$ and d; while the smooth finish of shaft neck e is the highest, with little wear on its surface. That is mainly on account of that shaft necks cooperating with bearing are under load for a long term, so there are gaps on their cooperation, relative motion between shaft necks and bearing is generated; and the property of material decreases somewhat due to the high temperature of working environment on supporting parts, which causes wear on the supporting pars of the component. 
Table 1 is the wearing capacity of all shaft necks of four invalid components:

\begin{tabular}{|c|c|c|c|c|}
\hline & $\begin{array}{c}\text { Invalid } \\
\text { component } 1\end{array}$ & $\begin{array}{c}\text { Invalid } \\
\text { component 2 }\end{array}$ & $\begin{array}{c}\text { Invalid } \\
\text { component 3 }\end{array}$ & $\begin{array}{c}\text { Invalid } \\
\text { component 4 }\end{array}$ \\
\hline Section a & 0.14 & 0.80 & 0.20 & 0.60 \\
\hline Section b & 0.06 & 0.10 & 0.06 & 0.04 \\
\hline Section c & 0.08 & 0.12 & 0.66 & 0.12 \\
\hline Section d & 0.02 & 0.02 & 0.08 & 0.08 \\
\hline
\end{tabular}

According to the analysis of data in this table: the wearing capacity of shaft neck a and c is large, with the wearing capacity above $0.1 \mathrm{~mm}$ basically and even reaching $0.8 \mathrm{~mm}$. Thus it can draw the conclusion that both shaft neck a and $\mathrm{c}$ are of diameters with large load, so the property of material should be improved during repair. The wearing capacity of shaft neck $b$ and $d$ is small, with the wearing capacity below $0.1 \mathrm{~mm}$ basically. Therefore, repair materials with small hardness can be taken into consideration during repair.

\section{Selection of repair technologies}

Determination of the highest temperature of repair technologies. In a copying machine, the requirement on position accuracy of roll shaft components is relatively high. In case of any deviation on the position accuracy of roll shaft components, the quality of copying documents will get worse, or even documents cannot be copied. Therefore, the deformation of components should be controlled strictly during repair. The deformation of components is mainly caused by phase transition of materials, of which one influence factor is temperature. Phase transition of material may be generated when phase-transition temperature is reached. In order to prevent component deformation, the temperature of heat-affected zones on components should be controlled during repair. Experiments show that the deformation of components can be controlled effectively, when the temperature is lower than the phase-transition temperature. For example, the phase-transition temperature of stainless steel 304 is $800^{\circ} \mathrm{C}$, so the local temperature of components should be controlled below $400^{\circ} \mathrm{C}$ during repair.

Repair technology selection and temperature control method. Considered from the perspective of temperature, cold spraying can be taken as the optimal repair technology, as temperature needs not to be controlled during cold spraying, since the temperature of drops for cold spraying is kept at about $100^{\circ} \mathrm{C}[2]$. As to other repair technologies such as likelaser welding and thermal spraying, temperature needs to be controlled during repair. During the implementation of likelaser welding or thermal spraying, temperature will accumulate on part of components. In order to prevent temperature accumulation, continuous processing time can be reduced and the interval can be increased during operation, so that the temperature of components can be reduced naturally in air.

2.3 Analysis on repair features of several technologies

1) Cold spraying

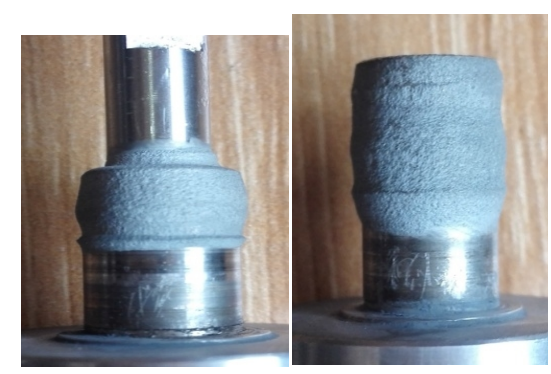

Fig. 3 Repaired by cold spraying 
With the least heat effect on components, the working mechanism of cold spraying technology is accelerating particles via high pressure gas, to make them strike the base at high speed, generate deformation, and bond with the base in the way of mechanical bond, during which the temperature is kept at about $100^{\circ} \mathrm{C}$, so the surface temperature of components need not to be controlled. However, the bonding intensity should be focused on, since the bonding mode of coating and base belong to pure mechanical bond basically.

2) Likelaser welding:

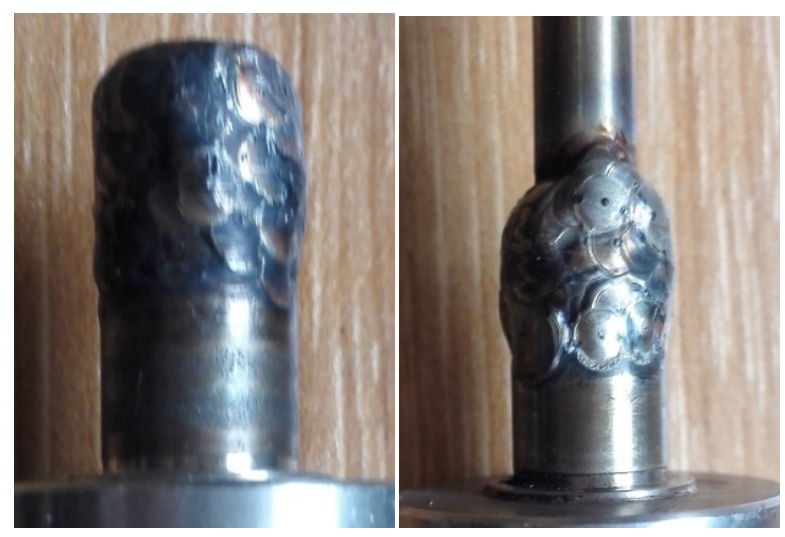

Fig. 4 Repaired by likelaser welding

Likelaser welding is a repair technology which bonds repair layer and base most firmly in the way of complete metallurgic bond[3]. However, as to the repair effect, the surface repaired through it is of poor flatness; and, its repair efficiency is low, since its operation process is accumulation of welding again and again.

3) Thermal spraying

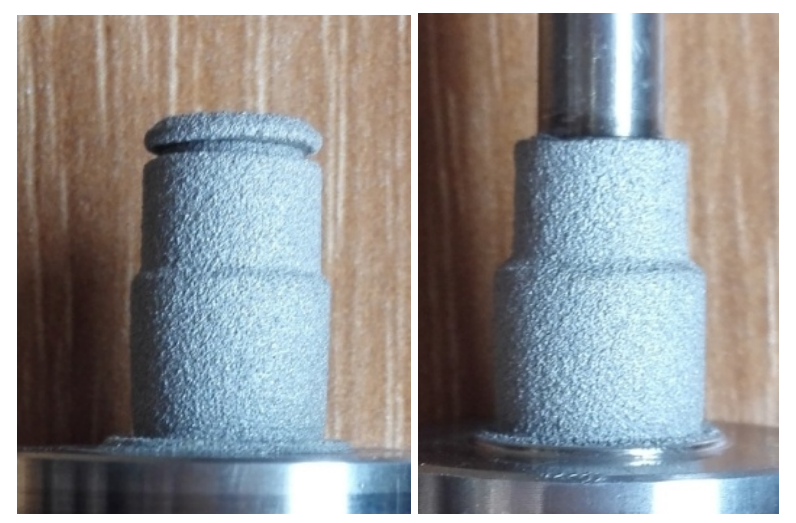

Fig. 5 Repaired by thermal spraying

As to thermal spraying, it works by heating particles, to make particles strike the base in molten condition, and bond with the base in semi-mechanical and semi-metallurgical way[4], so its bonding intensity between coating and base is larger than that of cold spraying. The surface repaired through thermal spraying is flat, and the heat-affected zone on component is monitored in real time during repair, so that serious thermal deformation will not be generated, as the heat effect on component taken by the technology is controlled. 


\section{Conclusion}

By integrating the advantages and disadvantages of all above technologies, it can be seen that:

1) The failure positions of roll shaft components of copying machines are supporting parts mostly, of which the failure is caused by excessive wear due to sliding friction occurred to supporting parts. They are ideal refabricating objects, with basically intact working surface, low repair workload, and high added value of repair.

2) In order to prevent deformation due to phase transition of components caused by repair technology, the temperature of heat-affected zone should be controlled.

3) As the bonding force between the attached layer and base, the recovery efficiency, and heat effect of different repair technologies cannot satisfy all requirements, repair technology should be selected on the basis of the features of components to be repaired, in order to realize comprehensive optimization of repair effect and economy.

\section{References}

[1] Xia Hui. Common Failures and Maintenance of Laser Copying Machine [J]. General Forum, 2013 (10): 386.

[2] Hiroshi KATANODA,Takeshi MATSUOKA,Kazuyasu MATSUO.Experimental Study on Shock Wave Structures in Constant-area Passage of Cold Spray Nozzle[J].Journal of Thermal Science, 2007(1):42.

[3] Sun Xiaofeng, Li Zhanming, Song Wei. Repairing the Sealing Faces on Shoulders of Diesel Motor through Likelaser Welding [J]. China Surface Engineering, 2015 (1): 121.

[4] P.Fauchais,A.Vardelle,B.Dussoubs.Quo Vadis Thermal Spraying[J].Journal of Thermal Spraying Technology,2001(10):44-46. 